\title{
Efficient preparation of organic substrate-RNA conjugates via in vitro transcription
}

\author{
Roberto Fiammengo, Kamil Musílek, and Andres Jäschke* \\ Insitut für Pharmazie and Molekulare Biotechnologie, Universität Heidelberg, Im \\ Neuenheimer Feld 364, 69120 Heidelberg, Germany.
}

Supporting information

*Corresponding author: Prof. Dr. Andres Jäschke, e-mail: jaeschke@uni-hd.de, Tel.: +49 622154 4851; Fax: +496221546430. 


\section{Experimental section}

General procedures. All reagents used were purchased from Aldrich, Fluka, or Acros Organics and used without further purification. Dry solvents (ACN, DMF, THF, Pyr) were purchased from Fluka (dry solvents over molecular sieves). Acid-free $\mathrm{CH}_{2} \mathrm{Cl}_{2}$ was obtained by storing the solvent on dry $\mathrm{K}_{2} \mathrm{CO}_{3}$ minimum for one night. Compound 7 was prepared according to literature. ${ }^{1,2}$ TLC analyses were carried out using silica gel plates Polygram ${ }^{\circledR}$ Sil $\mathrm{G}^{\mathbb{2}} \mathrm{UV}_{254}(40 \times 80 \mathrm{~mm})$ from Macherey-Nagel. Flash chromatography was carried out on silica gel $40 \mu \mathrm{m}$ from J.T. Baker. Ready-to-use Lobar $^{\circledR}$ columns from Merck (stationary phase LiChroprep ${ }^{\circledR}$ RP-18) were used for preparative reverse phase chromatography. Cation exchange was performed using a DOWEX ${ }^{\circledR} 50 \mathrm{WX} 8-200$ resin (sodium form). HPLC analysis were performed on a Agilent 1100 Series HPLC system equipped with an diode array detector using a Phenomenex ${ }^{\circledR}$ Luna 5U C18 column $(4.6 \times 250 \mathrm{~mm})$ and eluting with a gradient of 100 $\mathrm{mM}$ triethylammonium acetate (TEAA) $\mathrm{pH} 7.0$ (buffer A) and 80:20 ACN/TEAA (buffer B) at 1 $\mathrm{mL} / \mathrm{min}$. NMR spectra were recorded on Bruker AC-300, DRX-300, AM-360, or DRX-500 spectrometers. ${ }^{1} \mathrm{H}$ and ${ }^{13} \mathrm{C}\left\{{ }^{1} \mathrm{H}\right\}$ NMR spectra were calibrated to TMS on the basis of the relative chemical shift of the solvent as an internal standard. ${ }^{31} \mathrm{P}\left\{{ }^{1} \mathrm{H}\right\}$ NMR spectra were calibrated to an external standard $\left(85 \% \mathrm{H}_{3} \mathrm{PO}_{4}\right)$. Abbreviations used are as follows: $\mathrm{s}=$ singlet, $\mathrm{d}=$ doublet, $\mathrm{t}=$ triplet, $\mathrm{q}$ $=$ quartet, quin $=$ quintuplet, sext $=$ sextet, $\mathrm{sep}=$ septet, $\mathrm{m}=$ multiplet, $\mathrm{br}=$ broad signal. FAB and EI mass spectra were recorded on a JEOL JMS-700 sector field mass spectrometer. MALDI-TOF mass spectra were recorded on a Bruker BIFLEX III spectrometer.

List of abbreviations used in the synthetic procedures. TEA $=$ triethylamine, hex $=$ hexane, EA = ethylacetate, DMAP = 4-dimethylaminopyridine, DIPEA = ethyldiisopropylamine, $\mathrm{AcOH}=$ acetic acid, $\mathrm{MeOH}=$ methanol, EtOH = ethanol, DMT = 4,4'-Dimethoxytrityl, TCA = trichloroacetic acid, DCE = 1,2-dichloroethane, $\mathrm{TBAF}=$ tetra- $n$-butylammonium fluoride, $\mathrm{Et}_{2} \mathrm{O}=$ diethylether, $\mathrm{BTT}=5$ benzylthiotetrazole, DCI = 4,5-dicyanoimidazole, IMT = imidazolium triflate,

(4, 4'-Dimethoxytrityl)tetraethylene glycol (5). ${ }^{3}$ Tetraethylene glycol 4 (10.0 g, 51.5 mmol) was dried by coevaporation with toluene $(3 \times 25 \mathrm{~mL})$ and dissolved under argon in $40 \mathrm{~mL}$ of acid-free $\mathrm{CH}_{2} \mathrm{Cl}_{2}$ together with TEA $(2.6 \mathrm{~mL}, 19 \mathrm{mmol}, 0.37$ equiv) and DMAP $(63 \mathrm{mg}, 0.52 \mathrm{mmol}, 0.01$ equiv). A solution of 4,4'-dimethoxytrityl chloride (3.96 g, $11.7 \mathrm{mmol}, 0.23$ equiv) in $40 \mathrm{~mL}$ of acid-free $\mathrm{CH}_{2} \mathrm{Cl}_{2}$ was then slowly added at r.t. by syringe pump over 16 hours. After this period, the reaction mixture was diluted with $120 \mathrm{~mL}$ of $\mathrm{CH}_{2} \mathrm{Cl}_{2}$ and washed with $5 \% \mathrm{NaHCO}_{3}(100 \mathrm{~mL})$, water $(100 \mathrm{~mL})$, and brine $(2 \times 100 \mathrm{~mL})$, Drying over $\mathrm{Na}_{2} \mathrm{SO}_{4}$ and evaporation of the solvent under reduced pressure afforded the crude product as a yellow oil. Purification by flash chromatography (elution: from hex/EA 1:1 to 100\% EA, column preconditioned with the eluent containing 1\% TEA) gave 5 as pale yellow oil (4.60 g, $9.26 \mathrm{mmol}, 79 \%$ yield).

${ }^{1} \mathrm{H}$ NMR $\left(360 \mathrm{MHz} ;\left(\mathrm{CD}_{3}\right)_{2} \mathrm{CO}\right) \delta$ 7.53-7.47 (m, 2H), 7.41-7.17 (m, 7H), 6.91-6.83 (m, 4H), $3.75(\mathrm{~s}$ $6 \mathrm{H}), 3.67-3.50(\mathrm{~m}, 14 \mathrm{H}), 3.19(\mathrm{t}, 2 \mathrm{H}, \mathrm{J}=5.0 \mathrm{~Hz}) .{ }^{13} \mathrm{C} \mathrm{NMR}\left(90.5 \mathrm{MHz} ;\left(\mathrm{CD}_{3}\right)_{2} \mathrm{CO}\right) \delta 160.45,147.35$, 138.12, 131.87, 129.97, 129.46, 128.37, 114.77, 87.56, 74.50, 72.45, 72.31, 72.27, 72.16, 72.13, 65.04, 62.97, 56.44. FAB MS: m/z $496.3[\mathrm{M}]^{+}$(calculated for $\left[\mathrm{C}_{29} \mathrm{H}_{36} \mathrm{O}_{7}\right]^{+}$496.25).

(4, 4'-Dimethoxytrityl)tetraethylene glycol p-toluen sulfonate (6). ${ }^{3}$ Monoprotected tetraethylene glycol 5 (7.50 g, $15.1 \mathrm{mmol})$ was dried by coevaporation with toluene $(3 \times 35 \mathrm{~mL})$ and dissolved under argon in $80 \mathrm{~mL}$ of acid-free $\mathrm{CH}_{2} \mathrm{Cl}_{2}$ together with DMAP (92 mg, $0.76 \mathrm{mmol}, 0.05$ equiv) and TEA (6.3 ml, $45.0 \mathrm{mmol}, 3.0$ equiv). The reaction mixture was cooled to $0^{\circ} \mathrm{C}$ and $p$-toluensulfonyl chloride ( $3.17 \mathrm{~g}, 16.6 \mathrm{mmol}, 1.1$ equiv) was added. Stirring was continued for $12 \mathrm{~h}$ allowing slowly warming up to r.t. After this time no more starting material 5 could be detected by TLC (hex/EA 1:1). The reaction mixture was then diluted with EA $(200 \mathrm{ml})$ and washed with $5 \% \mathrm{NaHCO}_{3}(2 \times 80 \mathrm{ml})$, water $(80 \mathrm{ml})$, and brine $(2 \times 80 \mathrm{ml})$. Drying over $\mathrm{Na}_{2} \mathrm{SO}_{4}$ and removal of the solvent under reduced pressure afforded the product as viscous pale yellow oil $(9.78 \mathrm{~g}, 15.0 \mathrm{mmol}, 99 \%$ yield $)$. The product was sufficiently pure to be used in the next step. 
${ }^{1} \mathrm{H}$ NMR $\left(360 \mathrm{MHz} ;\left(\mathrm{CD}_{3}\right)_{2} \mathrm{CO}\right) \delta$ 7.81-7.76 (m, 2H), 7.51-7.41 (m, 4H), 7.38-7.17 (m, 7H), 6.89-6.83 (m, 4H), 4.12 (t, J=4.5 Hz, 2H), $3.76(\mathrm{~s}, 6 \mathrm{H}), 3.65-3.49(\mathrm{~m}, 12 \mathrm{H}), 3.17(\mathrm{t}, \mathrm{J}=5.0 \mathrm{~Hz}, 2 \mathrm{H}), 2.42(\mathrm{~s}, 3 \mathrm{H})$. ${ }^{13} \mathrm{C}$ NMR $\left(90.5 \mathrm{MHz} ;\left(\mathrm{CD}_{3}\right)_{2} \mathrm{CO}\right) \delta 160.49,147.37,146.69,138.15,135.31,131.89,131.78,129.99$, $129.68,129.48,128.40,114.79,87.58,72.47,72.30,72.26,72.22,72.18,71.62,70.26,65.07,56.46$. FAB MS: m/z $650.3[\mathrm{M}]^{+}$(calculated for $\left[\mathrm{C}_{36} \mathrm{H}_{42} \mathrm{O}_{9} \mathrm{~S}\right]^{+}$650.25).

(4,4'-Dimethoxytrityl)decaethylene glycol (2). Hexaethylene glycol (6.52 g, $23.1 \mathrm{mmol}, 3.0$ equiv) was dried by coevaporation with toluene $(3 \times 20 \mathrm{~mL})$, dissolved in $20 \mathrm{~mL}$ dry DMF under argon, and the solution was cooled to $0^{\circ} \mathrm{C}$. Sodium hydride $(0.61 \mathrm{~g} 60 \%$ in oil, $15.3 \mathrm{mmol}, 2.0$ equiv) was added and reaction mixture was stirred $10 \mathrm{~min}$ at $0^{\circ} \mathrm{C}$ and $15 \mathrm{~min}$ at r.t. The tosylated tetraethylene glycol 6 $(5.01 \mathrm{~g}, 7.70 \mathrm{mmol})$ was also dried by coevaporation with toluene $(3 \times 20 \mathrm{~mL})$, dissolved in $15 \mathrm{~mL}$ dry DMF and slowly added to the reaction mixture via syringe pump over $16 \mathrm{~h}$. The reaction was terminated after $20 \mathrm{~h}$ by dilution with $200 \mathrm{~mL}$ of $\mathrm{CH}_{2} \mathrm{Cl}_{2}$ and washing with water $(5 \times 100 \mathrm{~mL}), 5 \% \mathrm{NaHCO}_{3}$ $(100 \mathrm{~mL})$ and brine $(100 \mathrm{~mL})$. Drying over $\mathrm{Na}_{2} \mathrm{SO}_{4}$ and removal of the solvent under reduced pressure afforded the crude product as brownish oil. Purification by flash chromatography (elution: from EA/EtOH 92:8 to 60:40, column preconditioned with the eluent containing 1\% TEA) gave 2 as pale yellow oil (4.26 g, $5.60 \mathrm{mmol}, 73 \%)$.

${ }^{1} \mathrm{H}$ NMR $\left(300 \mathrm{MHz} ;\left(\mathrm{CD}_{3}\right)_{2} \mathrm{CO}\right) \delta$ 7.53-7.45 (m, 2H), 7.40-7.17 (m, 7H), 6.92-6.83 (m, 4H), $3.78(\mathrm{~s}$, $6 \mathrm{H}), 3.67-3.48(\mathrm{~m}, 38 \mathrm{H}), 3.17(\mathrm{t}, 2 \mathrm{H}, \mathrm{J}=5.0 \mathrm{~Hz}) .{ }^{13} \mathrm{C} \mathrm{NMR}\left(75.5 \mathrm{MHz} ;\left(\mathrm{CD}_{3}\right)_{2} \mathrm{CO}\right) \delta 160.49,147.37$, $138.16,131.89,129.99,129.48,128.40,114.80,87.59,74.52,72.49,72.32,72.21,72.08,71.87,65.08$, 62.98, 56.48. FAB MS: $\mathrm{m} / \mathrm{z} 760[\mathrm{M}]^{+}$(calculated for $\left.\left[\mathrm{C}_{41} \mathrm{H}_{60} \mathrm{O}_{13}\right]^{+} 760.40\right), \mathrm{m} / \mathrm{z} 783[\mathrm{M}+\mathrm{Na}]^{+}$ (calculated for $\left[\mathrm{C}_{41} \mathrm{H}_{60} \mathrm{O}_{13}+\mathrm{Na}\right]^{+}$783.39).

2',3'-Bis-(t-butyldimethylsilyl)guanosine-5'-O-( $\beta$-cyanoethyl- $N, N$-diisopropylphosphoramidite) (3). 2', 3'-Bis-(t-butyldimethylsilyl)guanosine $7^{1,2}(2.03 \mathrm{~g}, 3.97 \mathrm{mmol})$ was suspended in $10 \mathrm{~mL}$ of acidfree $\mathrm{CH}_{2} \mathrm{Cl}_{2}$ under argon and DIPEA was added $(2.17 \mathrm{~mL}, 12.57 \mathrm{mmol}, 3.2$ equiv). The mixture was cooled to $0^{\circ} \mathrm{C}$ before addition of 2-cyanoethyl- $N, N$-diisopropylchlorophosphoramidite $(1.0 \mathrm{~g}, 4.19$ mmol, 1.05 equiv). The mixture was stirred for $1 \mathrm{~h}$ during which the temperature was slowly raised to r.t. Eventually a clear solution was obtained and no more starting material could be detected by TLC (acetone/TEA 95:5). The reaction mixture was directly loaded on a silica gel column $(\varnothing=3 \mathrm{~cm}, 1=10$ $\mathrm{cm}$ ). Purification by flash chromatography (eluent acetone/TEA 98:2) afforded the clean product as white foam $(2.77 \mathrm{~g}, 3.89 \mathrm{mmol}, 98 \%$ yield). This product is a mixture of two diastereoisomer ( 1:1) due to the stereogenic nature of the phosphorous atom.

${ }^{31} \mathrm{P} \mathrm{NMR}\left(121 \mathrm{MHz} ;\left(\mathrm{CD}_{3}\right)_{2} \mathrm{CO}\right) \delta$ 148.80, 148.76. FAB HRMS: $/ \mathrm{z} 712.3815[\mathrm{M}+\mathrm{H}]^{+}$(calculated for
$\left.\left[\mathrm{C}_{31} \mathrm{H}_{59} \mathrm{~N}_{7} \mathrm{O}_{6} \mathrm{PSi}_{2}\right]^{+} 712.3803\right), 734.3635[\mathrm{M}+\mathrm{Na}]^{+}$(calculated for $\left.\left[\mathrm{C}_{31} \mathrm{H}_{58} \mathrm{~N}_{7} \mathrm{O}_{6} \mathrm{PSi}_{2}+\mathrm{Na}^{+}\right]^{+} 734.3622\right)$.

4-Chloromethylbenzaldehyde (9). ${ }^{4}$ Pyridinium chlorochromate (4.96 g, 23.0 mmol, 1.2 equiv) was dissolved in $60 \mathrm{~mL} \mathrm{CH} \mathrm{Cl}_{2}$ before addition of 4-chloromethylbenzyl alcohol (3.00 g, $\left.19.2 \mathrm{mmol}\right)$ The reaction mixture was stirred 2 hours at r.t., until disappearance of starting material as indicated by TLC $\left(\mathrm{CH}_{2} \mathrm{Cl}_{2}\right)$, and then poured into $200 \mathrm{~mL} \mathrm{Et} 2 \mathrm{O}$. The supernatant was removed and the gummy residue was triturated for 20 minutes with $200 \mathrm{~mL} \mathrm{Et} \mathrm{t}_{2} \mathrm{O}$. The combined organic solutions were washed with water $(3 \times 100 \mathrm{~mL}), 5 \% \mathrm{NaHCO}_{3}(2 \times 100 \mathrm{~mL})$ and brine $(100 \mathrm{~mL})$. Drying over $\mathrm{Na}_{2} \mathrm{SO}_{4}$ and removal of the solvent under reduced pressure afforded the crude product as white-off solid. Purification by flash chromatography (hex:EA 90:10) gave 9 as white crystalline solid (2.79 g, $18.0 \mathrm{mmol}, 94 \%)$.

${ }^{1} \mathrm{H}$ NMR $\left(300 \mathrm{MHz}, \mathrm{CDCl}_{3}\right) \delta 9.99(\mathrm{~s}, 1 \mathrm{H}), 7.85(\mathrm{~m}, 2 \mathrm{H}), 7.53(\mathrm{~m}, 2 \mathrm{H}), 4.60(\mathrm{~s}, 2 \mathrm{H}) .{ }^{13} \mathrm{C} \mathrm{NMR}$ $\left(75.5 \mathrm{MHz}, \mathrm{CDCl}_{3}\right) \delta 191.46,143.71,136.07,129.95,128.98,45.13$. m.p. $70-71^{\circ} \mathrm{C}$. EI MS: $\mathrm{m} / \mathrm{z} 154.0$ $[\mathrm{M}]^{+}$(calculated for $\left[\mathrm{C}_{8} \mathrm{H}_{7} \mathrm{ClO}\right]^{+}$154.02).

1-(4-chloromethylphenyl)prop-2-en-1-ol (10). 4-Cloromethylbenzaldehyde 9 ( $0.850 \mathrm{~g}, 5.50 \mathrm{mmol})$ was dissolved in $5 \mathrm{~mL}$ dry THF under argon. The solution was cooled to $-15^{\circ} \mathrm{C}$ and $5.8 \mathrm{~mL}$ of a $1 \mathrm{M}$ solution of vinylmagnesium bromide in THF ( $5.8 \mathrm{mmol}, 1.05$ equiv) were added. The reaction mixture 
was stirred at $-15^{\circ} \mathrm{C}$ for 30 minutes. Complete disappearance of the starting aldehyde was observed by TLC $\left(\mathrm{CH}_{2} \mathrm{Cl}_{2}\right)$. The reaction was then quenched with $5 \mathrm{~mL}$ of water and partioned between $1 \mathrm{M} \mathrm{HCl}$ $(30 \mathrm{~mL})$ and EA $(100 \mathrm{~mL})$. The organic phase was washed with $30 \mathrm{~mL} \mathrm{5 \%} \mathrm{NaHCO}_{3}$ and $30 \mathrm{~mL}$ brine, dried over $\mathrm{Na}_{2} \mathrm{SO}_{4}$, and evaporated under reduced pressure. Purification by flash chromatography (hex/EA 90:10) afforded the product as white colourless oil which solidifies upon standing (0.833 g, $4.56 \mathrm{mmol}, 83 \%$ yield).

${ }^{1} \mathrm{H}$ NMR $\left(360 \mathrm{MHz}, \mathrm{CDCl}_{3}\right) \delta 7.37(\mathrm{~m}, 4 \mathrm{H}), 6.02-5.96(\mathrm{~m}, 1 \mathrm{H}), 5.38-5.15(\mathrm{~m}, 3 \mathrm{H}), 4.58(\mathrm{~s}, 2 \mathrm{H}), 2.20$ (bs, 2H). ${ }^{13} \mathrm{C} \mathrm{NMR}\left(90 \mathrm{MHz}, \mathrm{CDCl}_{3}\right) \delta 142.86,140.02,139.91,128.74,126.66,115.35,74.93,45.87$. (EI MS: m/z $182.0[\mathrm{M}]^{+}$(calculated for $\left[\mathrm{C}_{10} \mathrm{H}_{11} \mathrm{ClO}\right]^{+}$182.05).

1-t-Butyldimethylsilyloxy-1-(4-chloromethylphenyl)prop-2-en (11). Allylic alcohol 10 (1.18 g, $6.46 \mathrm{mmol}$ ) was dissolved in $6 \mathrm{~mL}$ dry DMF under argon. Imidazole (1.45 g, $21.3 \mathrm{mmol}, 3.3$ equiv) and $t$-butylchlorodimethylsilane (1.26 g, $8.4 \mathrm{mmol}, 1.3$ equiv) were added and the reaction mixture was stirred $1 \mathrm{~h}$. Complete disappearance of the starting alcohol was observed by $\mathrm{TLC}\left(\mathrm{CH}_{2} \mathrm{Cl}_{2}\right)$. The reaction mixture was then diluted with $150 \mathrm{~mL}$ of $\mathrm{Et}_{2} \mathrm{O}$ and washed with water $(3 \times 30 \mathrm{~mL})$ and brine $(1 \times 30 \mathrm{~mL})$. The organic phase was dried over $\mathrm{Na}_{2} \mathrm{SO}_{4}$, and evaporated under reduced pressure affording the product as colourless oil $(1.90 \mathrm{~g}, 6.40 \mathrm{mmol}, 99 \%$ yield $)$. The product was generally used without further purification in the next step. An analytical sample for characterization was dissolved in $n$ pentane and filtered over a short plug of silica gel eluting with $n$-pentane.

${ }^{1} \mathrm{H}$ NMR (360 MHz, $\left.\mathrm{CDCl}_{3}\right) \delta 7.37(\mathrm{~m}, 4 \mathrm{H}), 5.93-5.81(\mathrm{~m}, 1 \mathrm{H}), 5.27(\mathrm{dt}, \mathrm{J}=17.0,1.51 \mathrm{~Hz}, 1 \mathrm{H}), 5.16$ $(\mathrm{dt}, \mathrm{J}=5.87,1.27 \mathrm{~Hz}, 1 \mathrm{H}), 5.05(\mathrm{dt}, \mathrm{J}=10.2,1.51 \mathrm{~Hz}, 1 \mathrm{H}), 4.54(\mathrm{~s}, 2 \mathrm{H}), 0.91(\mathrm{~s}, 9 \mathrm{H}), 0.07$ (s, 3H), 0.00 $(\mathrm{s}, 3 \mathrm{H}) .{ }^{13} \mathrm{C}$ NMR $\left(90 \mathrm{MHz}, \mathrm{CDCl}_{3}\right) \delta 144.11,141.47,136.21,128.45,126.32,113.59,75.64,46.02$, 25.85, 18.31, -4.64, -4.84. EI MS: m/z 296.0 [M] $]^{+}$(calculated for $\left[\mathrm{C}_{16} \mathrm{H}_{25} \mathrm{OClSi}\right]^{+} 296.14$ ).

N-(Benzyloxycarbonyl)-1,4-diaminobutane (13). 1,4-Diaminobutane 12 (4.0 g, 90.8 mmol, 1.0 equiv) and DMAP (55 mg, $0.45 \mathrm{mmol}, 0.005$ equiv) were dissolved in $150 \mathrm{~mL}$ of dry THF under argon. A solution of $N$-(benzyloxycarbonyloxy)-succinimide $(5.65 \mathrm{~g}, 22.7 \mathrm{mmol}, 0.25$ equiv) in $50 \mathrm{~mL}$ of dry THF was slowly added at r.t. by syringe pump over 23 hours. The reaction mixture was then filtered, and the THF removed under vacuum. The residue was taken up with $130 \mathrm{~mL}$ of water and the undissolved solid was filtered off. The aqueous solution was finally extracted with $\mathrm{CHCl}_{3}(4 \times 100 \mathrm{~mL})$ and the combined organic extracts were dried over $\mathrm{Na}_{2} \mathrm{SO}_{4}$. Evaporation of the solvent under reduced pressure afforded the crude product as pale yellow oil. Purification by flash chromatography (1butanol/AcOH$\left./ \mathrm{H}_{2} \mathrm{O} 3: 1: 1\right)$ gave pure $N$-(Benzyloxycarbonyl)-1,4-diaminobutane 13 (acetate salt) as pale yellow oil (2.98 g, $10.0 \mathrm{mmol}, 44 \%$ yield $)$.

${ }^{1} \mathrm{H}$ NMR $\left(360 \mathrm{MHz}, \mathrm{CD}_{3} \mathrm{OD}\right) \delta$ 7.37-7.26 (m, 5H), $3.15(\mathrm{t}, \mathrm{J}=6.6 \mathrm{~Hz}, 2 \mathrm{H}), 2.92(\mathrm{t}, \mathrm{J}=7.3 \mathrm{~Hz}, 2 \mathrm{H}), 1.91$ $(\mathrm{s}, 3 \mathrm{H}), 1.72-1.50(\mathrm{~m}, 4 \mathrm{H}) .{ }^{13} \mathrm{C} \mathrm{NMR}\left(90.5 \mathrm{MHz}, \mathrm{CD}_{3} \mathrm{OD}\right) \delta 179.69,158.97,138.41,129.50,129.01$, 128.80, 67.40, 41.04, 40.30, 27.87, 25.87, 23.86. MS-EI: m/z $222.2[\mathrm{M}]^{+}$(calculated for $\left[\mathrm{C}_{12} \mathrm{H}_{18} \mathrm{~N}_{2} \mathrm{O}_{2}\right]^{+}$ 222.14).

$N$-(Benzyloxycarbonyl)- $N$ '-(bromoacetyl)-1,4-diaminobutane (14). $\quad N$-(Benzyloxycarbonyl)-1,4diaminobutane (acetate salt) $13(2.58 \mathrm{~g}, 8.72 \mathrm{mmol})$ was dissolved in $35 \mathrm{~mL}$ of $\mathrm{CH}_{2} \mathrm{Cl}_{2}$ and $35 \mathrm{~mL}$ of saturated aqueous $\mathrm{Na}_{2} \mathrm{CO}_{3}$ were added. The mixture was vigorously stirred with a mechanical stirrer and cooled to $-10^{\circ} \mathrm{C}$ before addition of bromoacetyl bromide $(0.76 \mathrm{~mL}, 8.72 \mathrm{mmol}, 1 \mathrm{equiv})$. Stirring was continued for $30 \mathrm{~min}$ at $0^{\circ} \mathrm{C}$ before adding a second portion of bromoacetylbromide $(0.40 \mathrm{~mL}, 4.59$ mmol, 0.52 equiv). After $1 \mathrm{~h}$ the reaction mixture was poured into $150 \mathrm{~mL}$ of EA and $100 \mathrm{~mL}$ of water. The two phases were separated and the organic layer was washed with $5 \% \mathrm{NaHCO}_{3}(100 \mathrm{~mL}), 1 \mathrm{M} \mathrm{HCl}$ $(100 \mathrm{~mL})$, and brine $(2 \times 100 \mathrm{~mL})$. Drying over $\mathrm{Na}_{2} \mathrm{SO}_{4}$ and removal of the solvent under reduced pressure afforded the crude product as white solid. Purification by flash chromatography (hex:EA 1:1) gave 14 as white solid (2,33 g, $6.54 \mathrm{mmol}, 75 \%$ yield $)$. 
${ }^{1} \mathrm{H}$ NMR $\left(360 \mathrm{MHz}, \mathrm{CDCl}_{3}\right) \delta$ 7.37-7.27 (m, 5H), $6.70(\mathrm{bs}, 1 \mathrm{H}), 5.07(\mathrm{~s}, 2 \mathrm{H}), 5.03(\mathrm{bs}, 1 \mathrm{H}), 3.83(\mathrm{~s}$, 2H), 3.32-3.13 (m, 4H), $1.53(\mathrm{~m}, 4 \mathrm{H}) .{ }^{13} \mathrm{C} \mathrm{NMR}\left(90.5 \mathrm{MHz}, \mathrm{CDCl}_{3}\right) \delta 165.56,156.47,136.47,128.44$, 128.03, 127.97, 66.56, 40.43, 39.68, 29.12, 27.22, 26.34. EI MS: m/z 342.1, 344.1 [M] ${ }^{+}$(calculated for $\left[\mathrm{C}_{14} \mathrm{H}_{19} \mathrm{BrN}_{2} \mathrm{O}_{3}\right]^{+}$342.06), $263.2[\mathrm{M}-\mathrm{Br}]^{+}$(calculated for $\left[\mathrm{C}_{14} \mathrm{H}_{19} \mathrm{~N}_{2} \mathrm{O}_{3}\right]^{+}$263.14), 235.1, 237.0 [M$\left.\mathrm{PhCH}_{2} \mathrm{O}\right]^{+}$(calculated for $\left[\mathrm{C}_{7} \mathrm{H}_{12} \mathrm{~N}_{2} \mathrm{O}_{2}\right]^{+} 235.01$ ).

\section{1-(4,4'-Dimethoxytrityloxy)-29-(9-antrhrylmethyloxy)-3,6,9,12,15,18,21,24,27-}

nonaoxanonacosane (15). DMT-protected decaethylene glycol 2 (1.04 g, $1.31 \mathrm{mmol})$ was dried by coevaporation with toluene $(3 \times 15 \mathrm{~mL})$, dissolved in $7.0 \mathrm{~mL}$ dry ACN under argon, and sodium hydride (84 $\mathrm{mg} \mathrm{60 \%} \mathrm{in} \mathrm{oil,} 2.10 \mathrm{mmol}, 1.6$ equiv) was added. The reaction mixture was stirred $5 \mathrm{~min}$ at r.t. before addition of 9-chloromethylanthracene $(0.328 \mathrm{~g}, 1.44 \mathrm{mmol}, 1.1$ equiv) and $\mathrm{NaI}(0.237 \mathrm{~g}, 1.57$ mmol, 1.2 equiv). Stirring was then continued for $30 \mathrm{~min}$ at $40^{\circ} \mathrm{C}$, until disappearance of starting decaethylene glycol 2 as indicated by TLC (EA/MeOH 92:8). The reaction mixture was quenched with $8 \mathrm{~mL}$ of water, and partitioned between $80 \mathrm{~mL}$ of EA and additional $40 \mathrm{~mL}$ of water. The organic layer was then washed with water $(2 \times 40 \mathrm{~mL})$ and brine $(2 \times 40 \mathrm{~mL})$. Drying over $\mathrm{Na}_{2} \mathrm{SO}_{4}$ and removal of the solvent under reduced pressure afforded the crude product as yellow oil. Purification by flash chromatography (elution: from EA to $\mathrm{EA} / \mathrm{MeOH}$ 98:2, column preconditioned with the eluent containing 1\% TEA) gave 15 as pale yellow oil (0.911 g, $0.958 \mathrm{mmol}, 73 \%)$.

${ }^{1} \mathrm{H}$ NMR $\left(300 \mathrm{MHz},\left(\mathrm{CD}_{3}\right)_{2} \mathrm{CO}\right) \delta 8.55(\mathrm{~s}, 1 \mathrm{H}), 8.50(\mathrm{~d}, \mathrm{~J}=8.4 \mathrm{~Hz}, 2 \mathrm{H}), 8.06(\mathrm{~d}, \mathrm{~J}=8.4 \mathrm{~Hz}, 2 \mathrm{H}), 7.60$ $7.46(\mathrm{~m}, 6 \mathrm{H}), 7.40-7.18(\mathrm{~m}, 7 \mathrm{H}), 6.86(\mathrm{~m}, 4 \mathrm{H}), 5.54(\mathrm{~s}, 2 \mathrm{H}), 3.83(\mathrm{t}, \mathrm{J}=5.2 \mathrm{~Hz}, 2 \mathrm{H}), 3.75(\mathrm{~s}, 6 \mathrm{H}), 3.69-$ $3.46(\mathrm{~m}, 36 \mathrm{H}), 3.17(\mathrm{t}, \mathrm{J}=5.2 \mathrm{~Hz}, 2 \mathrm{H}) .{ }^{13} \mathrm{C} \mathrm{NMR}\left(75.5 \mathrm{MHz},\left(\mathrm{CD}_{3}\right)_{2} \mathrm{CO}\right) \delta 164.74,160.46,147.35$, $138.16,133.38,132.82,131.88,131.48,130.65,130.00,129.82,129.48,128.39,127.87,126.85$, 126.61, 114.81, 87.60, 72.55, 72.47, 72.28, 72.18, 71.87, 71.55, 66.71, 66.18, 65.08, 62.38, 56.48. FAB MS: m/z 974.2 $[\mathrm{M}+\mathrm{Na}]^{+}$(calculated for $\left[\mathrm{C}_{56} \mathrm{H}_{70} \mathrm{O}_{13}+\mathrm{Na}\right]^{+}$973.47), $951.2[\mathrm{M}]^{+}$(calculated for $\left[\mathrm{C}_{56} \mathrm{H}_{70} \mathrm{O}_{13}\right]^{+}$950.48).

\section{9-(9-antrhrylmethyloxy)-3,6,9,12,15,18,21,24,27-nonaoxanonacosan-1-ol (16). DMT-} deprotection of compound $15(1.25 \mathrm{~g}, 1.31 \mathrm{mmol})$ was achieved by dissolving the compound in $30 \mathrm{~mL}$ of a 3\% slution of TCA acid in DCE at r.t. After 5 min stirring, the reaction mixture was quenched by pouring it in $40 \mathrm{~mL}$ of saturated aqueous $\mathrm{NaHCO}_{3}$ and extracted with $50 \mathrm{~mL}$ of $\mathrm{CH}_{2} \mathrm{Cl}_{2}$. The organic layer was washed with $40 \mathrm{~mL}$ brine, dried over $\mathrm{Na}_{2} \mathrm{SO}_{4}$ and the solvent removed under reduced pressure to afford the crude product as pale yellow oil. Filtration over a $5 \mathrm{~cm}$ long silica gel plug eluting initially with $\mathrm{EA} / \mathrm{MeOH} 98: 2$ and then with $\mathrm{EA} / \mathrm{CH}_{2} \mathrm{Cl}_{2} / \mathrm{MeOH}$ 77:15:8 gave 16 as pale yellow oil $(0.750 \mathrm{~g}$, $1.16 \mathrm{mmol}, 88 \%)$.

${ }^{1} \mathrm{H}$ NMR $\left(300 \mathrm{MHz},\left(\mathrm{CD}_{3}\right)_{2} \mathrm{CO}\right) \delta 8.58-8.47(\mathrm{~m}, 3 \mathrm{H}), 8.07(\mathrm{~m}, 2 \mathrm{H}), 7.62-7.47(\mathrm{~m}, 4 \mathrm{H}), 5.55(\mathrm{~s}, 2 \mathrm{H})$, $3.84(\mathrm{~m}, 2 \mathrm{H}), 3.67(\mathrm{~m}, 2 \mathrm{H}), 3.67-3.48(\mathrm{~m}, 36 \mathrm{H}) .{ }^{13} \mathrm{C} \mathrm{NMR}\left(75.5 \mathrm{MHz},\left(\mathrm{CD}_{3}\right)_{2} \mathrm{CO}\right) \delta 133.40,132.83$, 131.49, 130.67, 129.83, 127.88, 126.87, 126.64, 74.494, 72.57, 72.17, 72.059, 71.55, 66.69, 62.94. FAB MS: m/z $671.8[\mathrm{M}+\mathrm{Na}]^{+}$(calculated for $\left[\mathrm{C}_{35} \mathrm{H}_{52} \mathrm{O}_{11}+\mathrm{Na}\right]^{+} 671.34$ ), $648.8[\mathrm{M}]^{+}$(calculated for $\left[\mathrm{C}_{35} \mathrm{H}_{52} \mathrm{O}_{11}\right]^{+}$648.35).

1-(4,4'-Dimethoxytrityloxy)-29-[4-(1-t-butyldimethylsilyloxyprop-2-en-1-yl)phenylmethylenoxy3,6,9,12,15,18,21,24,27-nonaoxanonacosane (17). DMT-protected decaethylenglycol 2 (0.875 g, 1.15 mmol) was dried by coevaporation with toluene $(3 \times 15 \mathrm{~mL})$, dissolved in $10.0 \mathrm{~mL}$ dry ACN under argon, and sodium hydride (74 $\mathrm{mg} 60 \%$ in oil, $1.84 \mathrm{mmol}, 1.6$ equiv) was added. The reaction mixture was stirred $5 \mathrm{~min}$ at r.t. before addition of $11(0.510 \mathrm{~g}, 1.70 \mathrm{mmol}, 1.5$ equiv) and $\mathrm{NaI}(0.189 \mathrm{~g}, 1.26$ mmol, 1.1 equiv). Stirring was then continued for $1.5 \mathrm{~h}$ at $40^{\circ} \mathrm{C}$, until disappearance of starting decaethylenglycol 2 as indicated by TLC (EA/MeOH 92:8). The reaction mixture was quenched with 8 $\mathrm{mL}$ of water, and partitioned between $100 \mathrm{~mL}$ of EA and additional $40 \mathrm{~mL}$ of water. The organic layer was then washed with water $(2 \times 40 \mathrm{~mL})$ and brine $(2 \times 40 \mathrm{~mL})$. Drying over $\mathrm{Na}_{2} \mathrm{SO}_{4}$ and removal of the solvent under reduced pressure afforded the crude product as pale yellow oil. Purification by flash 
chromatography (elution: from EA to EA/EtOH 95:5, column preconditioned with the eluent containing 1\% TEA) gave 17 as colorless oil (1.06 g, 1.04 mmol, 90\% yield).

${ }^{1} \mathrm{H}$ NMR $\left(300 \mathrm{MHz},\left(\mathrm{CD}_{3}\right)_{2} \mathrm{CO}\right) \delta 7.49(\mathrm{~m}, 2 \mathrm{H}), 7.39-7.18(\mathrm{~m}, 11 \mathrm{H}), 6.88(\mathrm{~m}, 4 \mathrm{H}), 5.99-5.84(\mathrm{~m}$, $1 \mathrm{H}), 5.36-5.22(\mathrm{~m}, 2 \mathrm{H}), 5.04(\mathrm{~m}, 1 \mathrm{H}), 4.52(\mathrm{~s}, 2 \mathrm{H}), 3.78(\mathrm{~s}, 6 \mathrm{H}), 3.68-3.52(\mathrm{~m}, 38 \mathrm{H}), 3.17(\mathrm{t}, \mathrm{J}=4.8 \mathrm{~Hz}$, 2H), $0.92(\mathrm{~s}, 9 \mathrm{H}), 0.10(\mathrm{~s}, 3 \mathrm{H}), 0.00(\mathrm{~s}, 3 \mathrm{H}) .{ }^{13} \mathrm{C} \mathrm{NMR}\left(75.5 \mathrm{MHz},\left(\mathrm{CD}_{3}\right)_{2} \mathrm{CO}\right) \delta 160.49,147.37,144.81$, $143.84,139.72,138.17,131.89,130.01,129.48,129.24,128.39,127.70,114.81,114.38,87.60,77.45$, 74.26, 72.51, 72.35, 72.33, 72.29, 72.24, 72.20, 71.47, 65.10, 56.48, 27.24, -3.45, -3.61. FAB MS: m/z $1020.7 \mathrm{CM}^{+} \quad$ (calculated for $\left[\mathrm{C}_{57} \mathrm{H}_{84} \mathrm{O}_{14} \mathrm{Si}\right]^{+}$1020.56), $1043.7 \quad[\mathrm{M}+\mathrm{Na}]^{+}$(calculated for $\left[\mathrm{C}_{57} \mathrm{H}_{84} \mathrm{O}_{14} \mathrm{Si}+\mathrm{Na}\right]^{+}$1043.55).

\section{1-(4,4'-Dimethoxytrityloxy)-29-[4-(1-hydroxyprop-2-en-1-yl)phenylmethylenoxy-}

3,6,9,12,15,18,21,24,27-nonaoxanonacosane (18). Compound 17 (2.563 g, $2.5 \mathrm{mmol})$ was dried by coevaporation with toluene $(3 \times 20 \mathrm{~mL})$ and dissolved under argon in $5 \mathrm{~mL}$ dry THF. $5 \mathrm{~mL}$ of a $1 \mathrm{M}$ solution of TBAF in THF (5.0 mmol, 2.0 equiv) were added and the reaction mixture was stirred $1 \mathrm{~h}$ at r.t., until all starting material was consumed according to TLC (EA:MeOH 92:8). The reaction mixture was then diluted with $200 \mathrm{~mL}$ EA, washed with water $(2 \times 100 \mathrm{~mL})$ and brine $(100 \mathrm{~mL})$, and dried over $\mathrm{Na}_{2} \mathrm{SO}_{4}$. The solvent was evaporated under reduced pressure to afford the crude product as pale yellow oil (2.28 g). Purification by flash chromatography (elution: from EA to EA/EtOH 90:10, column preconditioned with the eluent containing 1\% TEA) gave 18 as colorless oil (2.042 g, $2.3 \mathrm{mmol}, 90 \%$ yield).

${ }^{1} \mathrm{H}$ NMR $\left(300 \mathrm{MHz},\left(\mathrm{CD}_{3}\right)_{2} \mathrm{CO}\right) \delta 7.50(\mathrm{~m}, 2 \mathrm{H}), 7.39-7.17(\mathrm{~m}, 11 \mathrm{H}), 6.88(\mathrm{~m}, 4 \mathrm{H}), 6.06-5.92(\mathrm{~m}$, $1 \mathrm{H}), 5.34-5.13(\mathrm{~m}, 2 \mathrm{H}), 5.06(\mathrm{~m}, 1 \mathrm{H}), 4.52(\mathrm{~s}, 2 \mathrm{H}), 4.43(\mathrm{bs}, 1 \mathrm{H}), 3.78(\mathrm{~s}, 6 \mathrm{H}), 3.67-3.52(\mathrm{~m}, 38 \mathrm{H})$, $3.17(\mathrm{t}, \mathrm{J}=4.8 \mathrm{~Hz}, 2 \mathrm{H}) .{ }^{13} \mathrm{C} \mathrm{NMR}\left(75.5 \mathrm{MHz},\left(\mathrm{CD}_{3}\right)_{2} \mathrm{CO}\right) \delta 160.50,147.39,145.18,143.77,139.60$, $138.18,131.91,130.02,129.49,129.24,128.41,127.99,114.81,87.60,76.08,74.26,72.50,72.34$, 72.30, 72.28, 72.23, 72.20, 71.39, 65.10, 56.49. FAB MS: $\mathrm{m} / \mathrm{z} 945.7[\mathrm{M}+\mathrm{K}]^{+}$(calculated for $\left[\mathrm{C}_{51} \mathrm{H}_{70} \mathrm{O}_{14}+\mathrm{K}\right]^{+}$945.44), $929.7[\mathrm{M}+\mathrm{Na}]^{+}$(calculated for $\left[\mathrm{C}_{51} \mathrm{H}_{70} \mathrm{O}_{14}+\mathrm{Na}\right]^{+}$929.47), $906.6[\mathrm{M}]^{+}$ (calculated for $\left[\mathrm{C}_{51} \mathrm{H}_{70} \mathrm{O}_{14}\right]^{+}$906.48).

\section{1-(4,4'-Dimethoxytrityloxy)-29-[4-(1-benzyloxyprop-2-en-1-yl)]phenylmethylenoxy-}

3,6,9,12,15,18,21,24,27-nonaoxanonacosane (19). Compound 18 (0.597 g, $0.658 \mathrm{mmol})$ was dissolved under argon in $5 \mathrm{~mL}$ dry $\mathrm{ACN}$ and $\mathrm{NaH}$ ( $40 \mathrm{mg} \mathrm{60 \%} \mathrm{in} \mathrm{oil,} 0.99 \mathrm{mmol}, 1.5$ equiv) was added. The mixture was stirred at r.t. for $5 \mathrm{~min}$ before addition of benzylbromide ( $240 \mu \mathrm{L}, 1.97 \mathrm{mmol}, 3.0$ equiv). Stirring was continued for $1 \mathrm{~h}$ until complete disappearance of starting material as indicated by TLC (EA/MeOH 95:5). The reaction was quenched with $10 \mathrm{~mL}$ of water and successively partitioned between $200 \mathrm{~mL}$ of EA and $40 \mathrm{~mL}$ of water. The organic phase was further washed with brine $(2 \times 60 \mathrm{~mL})$, and dried over $\mathrm{Na}_{2} \mathrm{SO}_{4}$. The solvent was evaporated under reduced pressure to afford the crude product as yellow oil. Purification by flash chromatography (elution with EA, column preconditioned with the eluent containing 1\% TEA) gave 19 as pale yellow oil $(0.600 \mathrm{~g}, 0.602 \mathrm{mmol}$, $91 \%$ yield).

${ }^{1} \mathrm{H}$ NMR $\left(360 \mathrm{MHz},\left(\mathrm{CD}_{3}\right)_{2} \mathrm{CO}\right) \delta 7.51(\mathrm{~m}, 2 \mathrm{H}), 7.40-7.18(\mathrm{~m}, 16 \mathrm{H}), 6.88(\mathrm{~m}, 4 \mathrm{H}), 6.03-5.92(\mathrm{~m}, 1 \mathrm{H})$, 5.37-5.17 (m, 2H), $4.90(\mathrm{~m}, 1 \mathrm{H}), 4.54(\mathrm{~s}, 2 \mathrm{H}), 4.51(\mathrm{AB}, 2 \mathrm{H}), 3.77(\mathrm{~s}, 6 \mathrm{H}), 3.67-3.50(\mathrm{~m}, 38 \mathrm{H}), 3.18(\mathrm{t}$, $\mathrm{J}=5.0 \mathrm{~Hz}, 2 \mathrm{H}) .{ }^{13} \mathrm{C} \mathrm{NMR}\left(90.5 \mathrm{MHz},\left(\mathrm{CD}_{3}\right)_{2} \mathrm{CO}\right) \delta 160.44,147.33,142.24,141.18,140.69,140.22$, 138.12, 131.87, 130.03, 129.97, 129.46, 129.39, 129.24, 129.11, 128.57, 128.37, 117.22, 114.78, 87.55, 83.67, 74.17, 72.46, 72.29, 72.24, 72.20, 71.56, 71.46, 65.06, 56.47. FAB MS: m/z 1035.2 [M+K] (calculated for $\left[\mathrm{C}_{58} \mathrm{H}_{76} \mathrm{O}_{14}+\mathrm{K}\right]^{+}$1035.49), $1019.2[\mathrm{M}+\mathrm{Na}]^{+}$(calculated for $\left[\mathrm{C}_{58} \mathrm{H}_{76} \mathrm{O}_{14}+\mathrm{Na}\right]^{+}$1019.51), $\mathrm{m} / \mathrm{z} 1014.4\left[\mathrm{M}+\mathrm{H}_{2} \mathrm{O}\right]^{+}$(calculated for $\left[\mathrm{C}_{58} \mathrm{H}_{76} \mathrm{O}_{14}+\mathrm{H}_{2} \mathrm{O}\right]^{+}$1014.53).

29-[4-(1-benzyloxyprop-2-en-1-yl)phenylmethylenoxy-3,6,9,12,15,18,21,24,27-

nonaoxanonacosan-1-ol (20). DMT-deprotection of compound 19 (1.03 g, $1.03 \mathrm{mmol})$ was achieved by dissolving the compound in $30 \mathrm{~mL}$ of a $3 \%$ slution of TCA acid in DCE at r.t. After 5 min stirring, 
the reaction mixture was quenched by pouring it in $40 \mathrm{~mL}$ of saturated aqueous $\mathrm{NaHCO}_{3}$ and extracted with $50 \mathrm{~mL}$ of $\mathrm{CH}_{2} \mathrm{Cl}_{2}$. The organic layer was washed with $50 \mathrm{~mL}$ brine, dried over $\mathrm{Na}_{2} \mathrm{SO}_{4}$ and the solvent removed under reduced pressure to afford the crude product as pale yellow oil. Filtration over a $5 \mathrm{~cm}$ long silica gel plug eluting initially with EA/EtOH 98:2 and then from $\mathrm{EA} / \mathrm{CH}_{2} \mathrm{Cl}_{2} / \mathrm{EtOH}$ 77:15:8 to $\mathrm{EA} / \mathrm{CH}_{2} \mathrm{Cl}_{2} / \mathrm{EtOH}$ 40:50:10 gave 20 as colorless oil (0.640 g, 0.921 mmol, 89\% yield).

${ }^{1} \mathrm{H}$ NMR $\left(360 \mathrm{MHz},\left(\mathrm{CD}_{3}\right)_{2} \mathrm{CO}\right) \delta$ 7.40-7.24 (m, 9H), 6.03-5.93 (m, 1H), 5.37-5.17 (m, 2H), $4.92(\mathrm{~m}$, $1 \mathrm{H}), 4.55(\mathrm{~s}, 2 \mathrm{H}), 4.52(\mathrm{AB}, 2 \mathrm{H}), 3.65-3.50(\mathrm{~m}, 40 \mathrm{H}) .{ }^{13} \mathrm{C}$ NMR $\left(90.5 \mathrm{MHz},\left(\mathrm{CD}_{3}\right)_{2} \mathrm{CO}\right) \delta 141.29$, 130.09, 129.46, 129.32, 129.17, 128.65, 117.20, 103.74, 83.76, 74.53, 74.24, 72.24, 72.12, 71.63, 71.52, 63.00. FAB MS: m/z 733.8 $[\mathrm{M}+\mathrm{K}]^{+}$(calculated for $\left[\mathrm{C}_{37} \mathrm{H}_{58} \mathrm{O}_{12}+\mathrm{K}\right]^{+} 733.36$ ), $717.8[\mathrm{M}+\mathrm{Na}]^{+}$(calculated

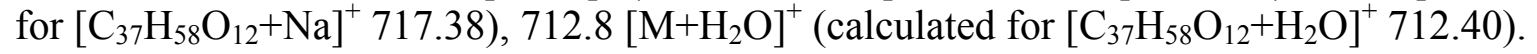

\section{1-(4,4'-Dimethoxytrityloxy)-29-[ $N$-(4-Benzyloxycarbonylamino)butyl]carbamoylmethylenoxy-} 3,6,9,12,15,18,21,24,27-nonaoxanonacosane (21). DMT-protected decaethylene glycol 2 (0.900 g, $1.18 \mathrm{mmol})$ was dried by coevaporation with toluene $(3 \times 15 \mathrm{~mL})$, dissolved in $6.5 \mathrm{~mL}$ dry ACN under argon, and sodium hydride ( $76 \mathrm{mg}, 1.88 \mathrm{mmol}, 1.6$ equiv) was added. The reaction mixture was stirred $5 \mathrm{~min}$ at r.t. before addition of 14 (0.607 g, $1.77 \mathrm{mmol}, 1.5$ equiv). Stirring was then continued for $1.5 \mathrm{~h}$ at $40^{\circ} \mathrm{C}$, until disappearance of starting decaethylene glycol 2 as indicated by TLC (Et $\left.2 \mathrm{O} / \mathrm{MeOH} 92: 8\right)$. The reaction mixture was quenched with $8 \mathrm{~mL}$ of water, and partitioned between $100 \mathrm{~mL}$ of EA and 40 $\mathrm{mL}$ of brine. The organic layer was then washed with brine $(2 \times 40 \mathrm{~mL})$. Drying over $\mathrm{Na}_{2} \mathrm{SO}_{4}$ and removal of the solvent under reduced pressure afforded the crude product as pale yellow oil. Purification by flash chromatography (elution from EA to EA/EtOH 87:13, column preconditioned with the eluent containing 1\% TEA) gave 17 as colorless oil $(0.751 \mathrm{~g}, 0.734 \mathrm{mmol}, 62 \%$ yield).

${ }^{1} \mathrm{H}$ NMR $\left(360 \mathrm{MHz},\left(\mathrm{CD}_{3}\right)_{2} \mathrm{CO}\right) \delta 7.50(\mathrm{~m}, 2 \mathrm{H}), 7.40-7.18(\mathrm{~m}, 12 \mathrm{H}), 6.88(\mathrm{~m}, 4 \mathrm{H}), 6.37(\mathrm{bs}, 1 \mathrm{H})$, $5.05(\mathrm{~s}, 2 \mathrm{H}), 4.87(\mathrm{bs}, 1 \mathrm{H}), 3.89(\mathrm{~s}, 2 \mathrm{H}), 3.78(\mathrm{~s}, 6 \mathrm{H}), 3.67-3.54(\mathrm{~m}, 38 \mathrm{H}), 3.28-3.13(\mathrm{~m}, 6 \mathrm{H}), 1.54(\mathrm{~m}$, $4 \mathrm{H}) .{ }^{13} \mathrm{C}$ NMR $\left(75.5 \mathrm{MHz},\left(\mathrm{CD}_{3}\right)_{2} \mathrm{CO}\right) \delta 171.17,160.54,158.19,147.40,139.58,138.21,131.92$, 130.18, 130.04, 129.60, 129.51, 128.43, 114.84, 87.64, 72.69, 72.51, 72.34, 72.20, 72.04, 71.88, 67.34, 65.12, 56.51, 42.30, 39.87, 29.06, 28.78. FAB MS: $\mathrm{m} / \mathrm{z} 1061.6[\mathrm{M}+\mathrm{K}]^{+}$(calculated for

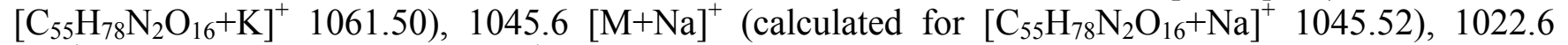
$[\mathrm{M}]^{+}$(calculated for $\left[\mathrm{C}_{55} \mathrm{H}_{78} \mathrm{~N}_{2} \mathrm{O}_{16}\right]^{+}$1022.54).

\section{9-[N-(4-Benzyloxycarbonylamino)butyl]carbamoylmethylenoxy-3,6,9,12,15,18,21,24,27-}

nonaoxanonacosan-1-ol (22). DMT-deprotection of compound $21(0.751 \mathrm{~g}, 0.734 \mathrm{mmol})$ was achieved by dissolving the compound in $30 \mathrm{~mL}$ of a 3\% slution of TCA acid in DCE at r.t. After 5 min stirring, the reaction mixture was quenched by pouring it in $40 \mathrm{~mL}$ of saturated aqueous $\mathrm{NaHCO}_{3}$ and extracted with $50 \mathrm{~mL}$ of $\mathrm{CH}_{2} \mathrm{Cl}_{2}$. The organic layer was washed with $50 \mathrm{~mL}$ brine, dried over $\mathrm{Na}_{2} \mathrm{SO}_{4}$ and the solvent removed under reduced pressure to afford the crude product as pale yellow oil. Filtration over a $5 \mathrm{~cm}$ long silica gel plug eluting initially with EA and then from EA/MeOH 92:8 to EA/MeOH/ $\mathrm{CH}_{2} \mathrm{Cl}_{2}$ 56:24:20 gave 21 as colorless oil ( $0.495 \mathrm{~g}, 0.686 \mathrm{mmol}, 93 \%$ yield).

${ }^{1} \mathrm{H}$ NMR $\left(360 \mathrm{MHz},\left(\mathrm{CD}_{3}\right)_{2} \mathrm{CO}\right) \delta 7.35(\mathrm{~m}, 5 \mathrm{H}), 6.35(\mathrm{bs}, 1 \mathrm{H}), 5.02(\mathrm{~s}, 2 \mathrm{H}), 3.88(\mathrm{~s}, 2 \mathrm{H}), 3.66-3.48(\mathrm{~m}$, $40 \mathrm{H}), 3.29-3.11(\mathrm{~m}, 4 \mathrm{H}), 2.85$ (bs, $1 \mathrm{H}), 1.54(\mathrm{~m}, 4 \mathrm{H}) .{ }^{13} \mathrm{C} \mathrm{NMR}\left(90.5 \mathrm{MHz},\left(\mathrm{CD}_{3}\right)_{2} \mathrm{CO}\right) \delta 171.10$, $158.16,139.58,130.17,129.60,129.53,74.53,72.72,72.23,72.11,72.04,71.90,67.30,62.99,42.28$, 39.83, 29.05, 28.80. FAB MS: $\mathrm{m} / \mathrm{z} 759.6[\mathrm{M}+\mathrm{K}]^{+}$(calculated for $\left[\mathrm{C}_{34} \mathrm{H}_{60} \mathrm{~N}_{2} \mathrm{O}_{14}+\mathrm{K}\right]^{+} 759.37$ ), 743.6 $[\mathrm{M}+\mathrm{Na}]^{+}$(calculated for $\left[\mathrm{C}_{34} \mathrm{H}_{60} \mathrm{~N}_{2} \mathrm{O}_{14}+\mathrm{Na}\right]^{+}$743.39), $721.6[\mathrm{M}+\mathrm{H}]^{+}$(calculated for $\left[\mathrm{C}_{34} \mathrm{H}_{60} \mathrm{~N}_{2} \mathrm{O}_{14}+\mathrm{H}\right]^{+}$ 721.41).

\section{9-(9-antrhrylmethyloxy)-3,6,9,12,15,18,21,24,27-nonaoxanonacosan-1-O-( $\beta$-cyanoethyl-N,N-}

diisopropyl)phosphoramidite (23). Alcohol 16 (0.486 g, $0.749 \mathrm{mmol})$ was dried by coevaporation with toluene $(3 \times 5 \mathrm{~mL})$, dissolved in $4 \mathrm{~mL}$ of acid-free $\mathrm{CH}_{2} \mathrm{Cl}_{2}$ under argon and DIPEA was added $(0.39$ $\mathrm{mL}, 2.2 \mathrm{mmol}, 3.0$ equiv). The mixture was cooled to $0^{\circ} \mathrm{C}$ before addition of 2-cyanoethyl- $N, N$ diisopropylchlorophosphoramidite $(0.20 \mathrm{~mL}, 0.90 \mathrm{mmol}, 1.2$ equiv). The mixture was stirred for $1 \mathrm{~h}$ 
during which the temperature was slowly raised to r.t. The reaction mixture was directly loaded on a silica gel column $(\varnothing=1.5 \mathrm{~cm}, 1=12 \mathrm{~cm})$. Purification by flash chromatography (eluent EA/TEA 95:5) afforded the product as pale yellow oil $(0.621 \mathrm{~g}, 0.731 \mathrm{mmol}, 98 \%$ yield $)$.

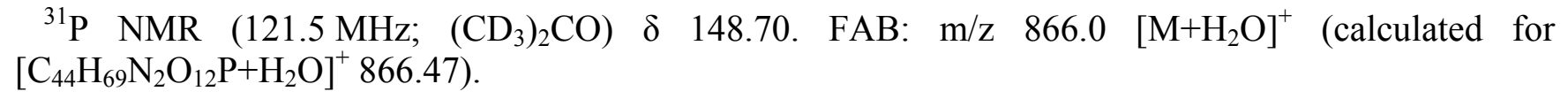

${ }^{31} \mathrm{P} \quad \mathrm{NMR} \quad\left(121.5 \mathrm{MHz} ; \quad\left(\mathrm{CD}_{3}\right)_{2} \mathrm{CO}\right) \quad \delta \quad 148.70$. $\mathrm{FAB}: \quad \mathrm{m} / \mathrm{z} \quad 866.0 \quad\left[\mathrm{M}+\mathrm{H}_{2} \mathrm{O}\right]^{+}$(calculated for $\left[\mathrm{C}_{44} \mathrm{H}_{69} \mathrm{~N}_{2} \mathrm{O}_{12} \mathrm{P}+\mathrm{H}_{2} \mathrm{O}\right]^{+}$866.47).

Initiator nucleotide 1a. Alcohol $20(0.354 \mathrm{~g}, 0.509 \mathrm{mmol})$ was dried by coevaporation with toluene $(3 \times 10 \mathrm{~mL})$ and $0.502 \mathrm{mg}$ of phosphoramidite $3(0.705 \mathrm{mmol}, 1.4$ equiv) were added under argon followed by $5 \mathrm{~mL}$ of dry ACN/THF 1:1 mixture and the activator IMT (63 mg, $0.29 \mathrm{mmol}, 0.56$ equiv). The reaction was stirred at r.t. for $1 \mathrm{~h}$. The coupling reaction was then stopped by addition of $0.65 \mathrm{~mL}$ of $t$-butylhydroperoxide (5.2 mmol, 10 equiv). After $30 \mathrm{~min}$ stirring, all the volatiles were removed under vacuum and the thick oily residue was taken up in $5.0 \mathrm{~mL} 1 \mathrm{M}$ TBAF in THF (5.0 mmol, 10 equiv) under argon. After $1 \mathrm{~h}$ stirring, full deprotection was obtained according to TLC (RP-18 plates, $\mathrm{ACN} / \mathrm{H}_{2} \mathrm{O}$ 1:1). The THF was removed under vacuum and the residue was taken up with $8 \mathrm{~mL}$ of a 8:2 $\mathrm{ACN} / \mathrm{H}_{2} \mathrm{O}$ mixture, filtered through a $0.22 \mu \mathrm{M}$ membrane filter, and purified by preparative reverse phase chromatography (RP-18, elution from $\mathrm{ACN} / \mathrm{H}_{2} \mathrm{O} 8: 2$ to $\mathrm{ACN} / \mathrm{H}_{2} \mathrm{O}$ 1:1). The fractions containing the product were concentrated under vacuum to remove most of the ACN and lyophilized. Tetrabutylammonium cations were exchanged for sodium on an ion-exchange resin (see general information) loaded in a column $(\varnothing=1.5 \mathrm{~cm}, 1=14 \mathrm{~cm})$ eluting with water. The eluate containing the product was lyophilized. An additional preparative reverse phase chromatography was finally carried out to remove any excess salt. The pure product was obtained after lyophilization as white hygroscopic solid (0.221 g, $0.208 \mathrm{mmol}, 41 \%$ yield).

${ }^{1} \mathrm{H}$ NMR $\left(360 \mathrm{MHz},\left(\mathrm{D}_{2} \mathrm{O}\right) \delta 8.05(\mathrm{~s}, 1 \mathrm{H}), 7.44-7.30(\mathrm{~m}, 9 \mathrm{H}), 6.09-5.97(\mathrm{~m}, 1 \mathrm{H}), 5.87(\mathrm{~d}, \mathrm{~J}=5.8 \mathrm{~Hz}\right.$, $1 \mathrm{H}), 5.35-5.25(\mathrm{~m}, 2 \mathrm{H}), 4.50(\mathrm{~d}, \mathrm{~J}=7.0 \mathrm{~Hz}, 1 \mathrm{H}), 4.58(\mathrm{AB}, 2 \mathrm{H}), 4.53-4.42(\mathrm{~m}, 3 \mathrm{H}), 4.29(\mathrm{~m}, 1 \mathrm{H}), 4.08(\mathrm{t}$, $\mathrm{J}=3.8 \mathrm{~Hz}, 2 \mathrm{H}), 3.89(\mathrm{~m}, 2 \mathrm{H}), 3.71-3.51(\mathrm{~m}, 40 \mathrm{H}) .{ }^{13} \mathrm{C} \mathrm{NMR}\left(75.5 \mathrm{MHz}, \mathrm{H}_{2} \mathrm{O} / \mathrm{D}_{2} \mathrm{O} 9: 1\right) \delta 161.27$, $156.70,154.38,142.79,140.89,140.56,140.17,140.02,131.15,131.01,130.51,129.73,119.73118 .70$, 89.81, 86.47, 86.36, 84.45, 76.51, 75.02, 73.22, 72.77, 72.67, 72.54, 72.32, 71.63, 67.63, 67.59, 67.44, 67.37. ${ }^{31} \mathrm{P}$ NMR (121.5 MHz, $\left.\mathrm{H}_{2} \mathrm{O} / \mathrm{D}_{2} \mathrm{O} 9: 1\right): \delta$ 0.289. MALDI TOF MS: m/z 1039.4 [M] (calculated for $\left[\mathrm{C}_{45} \mathrm{H}_{64} \mathrm{~N}_{5} \mathrm{O}_{18} \mathrm{P}\right]^{-}$1039.44).

\section{Initiator nucleotide $\mathbf{1 b}$.}

Coupling of phosphoramidite 23 with alcohol 7. A mixture of diprotectd guanosine 7 (0.903 g, 1.76 mmol, 1.2 equiv) and BTT (2.88 g, $15 \mathrm{mmol}, 10$ equiv) was dried by coevaporation with toluene $(4 \times 20 \mathrm{~mL})$, suspended in $20 \mathrm{~mL}$ dry $\mathrm{ACN}$ under argon, and cooled to $0^{\circ} \mathrm{C}$. A solution of phosphoramidite $23(1.27 \mathrm{~g}, 1.5 \mathrm{mmol})$ in $5 \mathrm{~mL}$ dry ACN was then added. After 5 minutes the cooling bath was removed and the mixture was allowed to reach r.t.. The coupling reaction was stopped after 9 $\mathrm{h}$ by addition of $1.9 \mathrm{~mL}$ of $t$-butylhydroperoxide ( $15 \mathrm{mmol}, 10$ equiv). After $30 \mathrm{~min}$ stirring, the reaction mixture was poured into $50 \mathrm{~mL}$ of $5 \% \mathrm{NaHSO}_{3}$ and extracted with $300 \mathrm{~mL}$ of EA. The organic layer was washed with $100 \mathrm{~mL}$ water, $100 \mathrm{~mL}$ brine, and dried over $\mathrm{Na}_{2} \mathrm{SO}_{4}$. The solvent was removed under reduced pressure affording the crude product as yellow paste. Excess BTT was removed by filtration over a $10 \mathrm{~cm}$ long silica gel plug eluting with $\mathrm{EA} / \mathrm{EtOH}$ 95:5 and then with $\mathrm{EA} / \mathrm{EtOH} / \mathrm{CH}_{2} \mathrm{Cl}_{2}$ 25:50:25 to recover the product. Removal of the solvent gave a yellow oily residue which was dissolved in 7.5 $\mathrm{mL} 1 \mathrm{M}$ TBAF in THF ( $7.5 \mathrm{mmol}, 5$ equiv) under argon. After $1 \mathrm{~h}$ stirring, full deprotection was obtained according to TLC (RP-18 plates, $\mathrm{ACN} / \mathrm{H}_{2} \mathrm{O} 1: 1$ ). The THF was removed under vacuum and the residue was taken up with $5 \mathrm{~mL}$ of a $8: 2 \mathrm{ACN} / \mathrm{H}_{2} \mathrm{O}$ mixture, filtered through a $0.22 \mu \mathrm{M}$ membrane filter, and purified by preparative reverse phase chromatography, ion exchange and a second reverse phase chromatography as described for 1a. The pure product was obtained after lyophilization as pale yellow, hygroscopic solid (0.306 g, $0.301 \mathrm{mmol}, 20 \%$ yield). 
Coupling of phosphoramidite 3 with alcohol 16. Alcohol $16(0.490 \mathrm{~g}, 0.755 \mathrm{mmol})$ was dried by coevaporation with toluene $(3 \times 10 \mathrm{~mL})$ and $9.0 \mathrm{~mL}$ of a $0.1 \mathrm{M}$ solution of phosphoramidite $3(0.90$ mmol, 1.2 equiv) in dry THF were added under argon. DCI was then added as activator $(0.090 \mathrm{~g}, 0.755$ mmol, 1 equiv) and the reaction was stirred at r.t. for $20 \mathrm{~min}$. The coupling reaction was then stopped by addition of $0.95 \mathrm{~mL}$ of $t$-butylhydroperoxide ( $7.6 \mathrm{mmol}, 10$ equiv). After $30 \mathrm{~min}$ stirring, all the volatiles were removed under vacuum and the thick oily residue was taken up in $4.5 \mathrm{~mL} 1 \mathrm{M}$ TBAF in THF (4.5 mmol, 6 equiv) under argon. After $1 \mathrm{~h}$ stirring, full deprotection was obtained according to TLC (RP-18 plates, $\mathrm{ACN} / \mathrm{H}_{2} \mathrm{O}$ 1:1). The THF was removed under vacuum and the residue was taken up with $3 \mathrm{~mL}$ of a $8: 2 \mathrm{ACN} / \mathrm{H}_{2} \mathrm{O}$ mixture, filtered through a $0.22 \mu \mathrm{M}$ membrane filter, and purified by preparative reverse phase chromatography, ion exchange and a second reverse phase chromatography as described for 1a. The pure product was obtained after lyophilization as pale yellow, hygroscopic solid (0.234 g, $0.230 \mathrm{mmol}, 31 \%$ yield).

${ }^{1} \mathrm{H}$ NMR $\left(360 \mathrm{MHz},\left(\mathrm{D}_{2} \mathrm{O}\right) \delta 8.32(\mathrm{~s}, 1 \mathrm{H}), 8.25(\mathrm{~d}, \mathrm{~J}=8.5 \mathrm{~Hz}, 2 \mathrm{H}), 7.91(\mathrm{~d}, \mathrm{~J}=8.5 \mathrm{~Hz}, 2 \mathrm{H}), 7.83(\mathrm{~s}\right.$, 1H), 7.55-7.40 (m, 4H), $5.62(\mathrm{~d}, \mathrm{~J}=5.0 \mathrm{~Hz}, 1 \mathrm{H}), 5.40(\mathrm{~s}, 2 \mathrm{H}), 4.53(\mathrm{t}, \mathrm{J}=5.0 \mathrm{~Hz}, 1 \mathrm{H}), 4.40(\mathrm{t}, \mathrm{J}=4.5 \mathrm{~Hz}$, $1 \mathrm{H}), 4.25(\mathrm{bs}, 1 \mathrm{H}), 4.08(\mathrm{~m}, 2 \mathrm{H}), 3.93-3.79(\mathrm{~m}, 4 \mathrm{H}), 3.70-3.36(\mathrm{~m}, 40 \mathrm{H}) .{ }^{13} \mathrm{C} \mathrm{NMR}(75.5 \mathrm{MHz}$, $\left.\mathrm{H}_{2} \mathrm{O} / \mathrm{D}_{2} \mathrm{O} 9: 1\right) \delta 160.98,156.39,154.03,139.69,133.56,133.13,131.38,130.86,130.68,129.09$, $127.74,126.63,118.51,89.78,86.29,86.18,79.58,73.10,72.74,72.64,72.42,72.17,71.68,67.57$, 67.51, 67.42, 67.34, 67.09. ${ }^{31} \mathrm{P}$ NMR (121.5 MHz, $\left.\mathrm{H}_{2} \mathrm{O} / \mathrm{D}_{2} \mathrm{O} 9: 1\right): \delta 0.303$. MALDI TOF MS: m/z 994.7 $[\mathrm{M}]^{-}$(calculated for $\left[\mathrm{C}_{45} \mathrm{H}_{64} \mathrm{~N}_{5} \mathrm{O}_{18} \mathrm{P}\right]^{-}$993.40).

Initiator nucleotide 1c. Alcohol $22(0.260 \mathrm{~g}, 0.360 \mathrm{mmol})$ was dried by coevaporation with toluene $(3 \times 5 \mathrm{~mL})$ and $4.4 \mathrm{~mL}$ of a $0.1 \mathrm{M}$ solution of phosphoramidite $3(0.44 \mathrm{mmol}, 1.2$ equiv $)$ in dry THF were added under argon. DCI was then added as activator $(0.131 \mathrm{~g}, 1.10 \mathrm{mmol}, 3.0$ equiv) and the reaction was stirred at r.t. for $1 \mathrm{~h}$. The coupling reaction was then stopped by addition of $0.45 \mathrm{~mL}$ of $t$ butylhydroperoxide ( $3.6 \mathrm{mmol}, 10$ equiv). After $30 \mathrm{~min}$ stirring, all the volatiles were removed under vacuum and the thick oily residue was taken up in $3.6 \mathrm{~mL} 1 \mathrm{M}$ TBAF in THF (3.6 mmol, 10 equiv) under argon. After $3 \mathrm{~h}$ stirring, full deprotection was obtained according to TLC (RP-18 plates, $\mathrm{ACN} / \mathrm{H}_{2} \mathrm{O}$ 1:1). The THF was removed under vacuum and the residue was taken up with $6 \mathrm{~mL}$ of a 8:2 $\mathrm{ACN} / \mathrm{H}_{2} \mathrm{O}$ mixture, filtered through a $0.22 \mu \mathrm{M}$ membrane filter, and purified by preparative reverse phase chromatography, ion exchange and a second reverse phase chromatography as described for 1a. The pure product was obtained after lyophilization as white hygroscopic solid $(0.139 \mathrm{~g}, 0.131 \mathrm{mmol}$, $36 \%$ yield).

${ }^{1} \mathrm{H}$ NMR $\left(360 \mathrm{MHz},\left(\mathrm{D}_{2} \mathrm{O}\right) \delta 8.12(\mathrm{~s}, 1 \mathrm{H}), 7.42-7.30(\mathrm{~m}, 5 \mathrm{H}), 5.90(\mathrm{~d}, \mathrm{~J}=5.7 \mathrm{~Hz}, 1 \mathrm{H}), 5.05(\mathrm{~s}, 2 \mathrm{H})\right.$, $4.49(\mathrm{t}, \mathrm{J}=4.5 \mathrm{~Hz}, 1 \mathrm{H}), 4.31(\mathrm{~m}, 1 \mathrm{H}), 4.10(\mathrm{~m}, 2 \mathrm{H}), 4.03(\mathrm{~s}, 2 \mathrm{H}), 3.92(\mathrm{~m}, 2 \mathrm{H}), 3.73-3.54(\mathrm{~m}, 40 \mathrm{H}) .{ }^{13} \mathrm{C}$ $\mathrm{NMR}\left(125.8 \mathrm{MHz}, \mathrm{H}_{2} \mathrm{O} / \mathrm{D}_{2} \mathrm{O}\right.$ 9:1) $\delta 175.02,161.21,161.04,156.76,154.31,139.98,139.24,131.43$, $130.98,130.26,118.41,89.82,86.47,86.40,76.41,73.17,73.05,72.73,72.67,72.36,72.30,72.22$, 69.39, 67.59, 67.55, 67.43, 67.38, 42.93, 41.41, 29.11, 28.53. ${ }^{31} \mathrm{P}$ NMR $\left(121.5 \mathrm{MHz}, \mathrm{H}_{2} \mathrm{O} / \mathrm{D}_{2} \mathrm{O} 9: 1\right): \delta$ 0.352. MALDI TOF MS: m/z 1065.6 [M] (calculated for $\left[\mathrm{C}_{44} \mathrm{H}_{72} \mathrm{~N}_{7} \mathrm{O}_{21} \mathrm{P}\right]^{-}$1065.45).

Initiator nucleotide 1d. Compound 1c $(85.4 \mathrm{mg}, 0.078 \mathrm{mmol})$ was dissolved in degassed $\mathrm{MeOH}$ and $29 \mathrm{mg}$ of $10 \% \mathrm{Pd}$ on charcoal were added. The hydrogenation reaction was conducted under $1 \mathrm{~atm} \mathrm{H}_{2}$. After $2 \mathrm{~h}$ stirring, full deprotection was obtained according to TLC (RP-18 plates, ACN/ $\mathrm{H}_{2} \mathrm{O}$ 1:1). The reaction mixture was then filtered through $C$ elite ${ }^{\circledR}$ and the solvent removed under vacuum. The residue was taken up with $2 \mathrm{~mL}$ of $\mathrm{H}_{2} \mathrm{O}$, filtered through a $0.22 \mu \mathrm{M}$ membrane filter, and purified by preparative reverse phase chromatography (elution from 9:1 to 75:25 $\mathrm{H}_{2} \mathrm{O} / \mathrm{ACN}$ ). Lyophilization afforded the pure product as white hygroscopic solid $(71.1 \mathrm{mg}, 0.074 \mathrm{mmol}, 94 \%$ yield).

${ }^{1} \mathrm{H}$ NMR $\left(300 \mathrm{MHz},\left(\mathrm{D}_{2} \mathrm{O}\right) \delta 8.05(\mathrm{~s}, 1 \mathrm{H}), 5.87(\mathrm{~d}, \mathrm{~J}=5.7 \mathrm{~Hz}, 1 \mathrm{H}), 4.75(\mathrm{t}, \mathrm{J}=5.5 \mathrm{~Hz}, 2 \mathrm{H}), 4.47(\mathrm{t}\right.$, $\mathrm{J}=4.4 \mathrm{~Hz}, 1 \mathrm{H}), 4.28(\mathrm{~m}, 1 \mathrm{H}), 4.07(\mathrm{~m}, 2 \mathrm{H}), 4.03(\mathrm{~s}, 2 \mathrm{H}), 3.88(\mathrm{~m}, 2 \mathrm{H}), 3.71-3.55(\mathrm{~m}, 40 \mathrm{H}) .{ }^{13} \mathrm{C} \mathrm{NMR}$ $\left(75.5 \mathrm{MHz}, \mathrm{D}_{2} \mathrm{O}\right) \delta 175.10,161.31,156.55,154.45,140.11,118.82,89.68,86.43,86.32,76.25,73.13$, $73.00,72.72,72.63,72.26,67.64,67.58,67.40,67.32,41.79,40.86,28.25,26.86 .{ }^{31} \mathrm{P} \mathrm{NMR}$ 
$\left(121.5 \mathrm{MHz}, \mathrm{D}_{2} \mathrm{O}\right): \delta$ 0.460. MALDI TOF MS: m/z $932.2[\mathrm{M}]^{-}$(calculated for $\left[\mathrm{C}_{36} \mathrm{H}_{66} \mathrm{~N}_{7} \mathrm{O}_{19} \mathrm{P}\right]^{-}$ 931.42).

The purity of initiator nucleotides 1a-d was confirmed by analytical HPLC. The used gradient, and the observed retention times are showed in Figure S1.

\begin{tabular}{c|cc|c}
$\begin{array}{c}\text { Time } \\
(\mathrm{min})\end{array}$ & $\begin{array}{c}\text { Buffer B } \\
(\%)\end{array}$ & Compound & $\begin{array}{c}\text { Retention time } \\
(\mathrm{min})\end{array}$ \\
\hline \multirow{2}{*}{} & 5 & $\mathbf{1 a}$ & 36.3 \\
25 & 40 & $\mathbf{1 b}$ & 34.4 \\
40 & 80 & $\mathbf{1 c}$ & 27.6 \\
$\mathbf{4 5}$ & 100 & $\mathbf{1 d}$ & 14.3
\end{tabular}
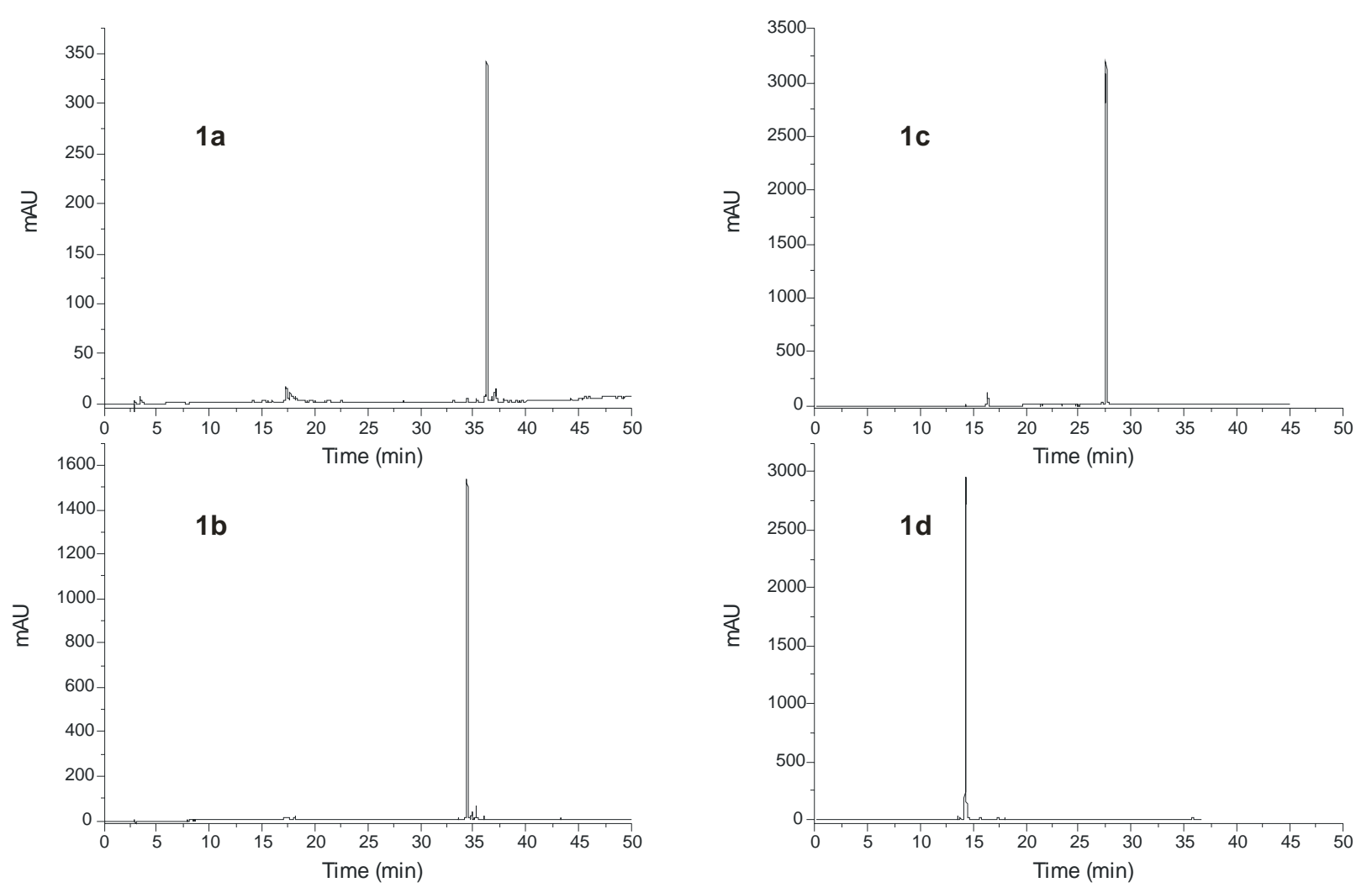

Figure S1. HPLC chromatograms for initiator nucleotides 1a-d.

Preparation of aqueous solutions of initiator nucleotides 1a-d. Initiator nucleotides 1a-d were dissolved in Milli- $Q^{\circledR}$ water and filtered through a $0.22 \mu \mathrm{M}$ membrane filter. The solutions concentrations were determined via UV (Amersham Biosciences Ultrospec 2100 pro UV-vis spectrophotometer). Calibration curves were prepared using either guanosine or anthracenemethyl decaethylene glycol 16 as model compounds for 1a, 1c, 1d and $\mathbf{1 b}$ respectively. For guanosine, the absorbance at $260 \mathrm{~nm}$ of 6 aqueous solutions of in the range $7.48-59.9 \mu \mathrm{M}$ was measured. For compound 16, the absorbance at $365 \mathrm{~nm}$ of 6 aqueous solutions in the range $20.0-150 \mu \mathrm{M}$ was measured. The coefficient of determination $\left(\mathrm{R}^{2}\right)$ for the calibration curves was 0,999 in both cases.

T7 RNAP transcriptions. T7 transcription were performed using a 44-mer double stranded DNA template obtained by heating a 1:1 mixture of sense and antisense DNA strands in the transcription 
buffer (vide infra) at $90^{\circ} \mathrm{C}$ for 3 minutes and slowly cooling down to room temperature in $1 \mathrm{~h}$. The two synthetic oligonucleotides (IBA Goettingen, Germany) have the following sequences:

Sense $\quad 5$ '-TCT AAT ACG ACT CAC TAT AGG AGC TCA GCC TAC GAG CCT GAG CC-3' Antisense 3'-AGA TTA TGC TGA GTG ATA TCC TCG AGT CGG ATG CTC GGA CTC GG-5'

Transcription reactions $(25-50 \mu \mathrm{l})$ were carried out in a buffer where final concentrations were: 40 $\mathrm{mM}$ Tris- $\mathrm{HCl}$ ( $\mathrm{pH} 8.1$ ), $22 \mathrm{mM} \mathrm{MgCl} 2,1 \mathrm{mM}$ spermidine, $0.01 \%$ Triton X-100, $10 \mathrm{mM}$ dithiothreitol, $50 \mu \mathrm{g} / \mathrm{mL}$ bovine serum albumin. ATP, CTP, and UTP were always used in 1:1:1 ratio and their concentration varied in the range $1-4 \mathrm{mM}$. GTP concentration was varied independently in the range $0.2-2 \mathrm{mM}$, as specified in the text and figures for each experiment. Initiator nucleotides 1a-1d were all used at $4 \mathrm{mM}$ final concentration. The template was added at a final concentration of $0.2 \mu \mathrm{M}$. $0.5 \mu \mathrm{M}$ $\left[\alpha{ }^{32} \mathrm{P}\right]$ CTP $(20 \mu \mathrm{Ci} / \mu \mathrm{L}$ from Amersham Biosciences) was included in the reaction mixtures to radiolabel the transcripts. The reactions were started by addition of T7 RNAP (Fermentas, final concentration $8 \mathrm{U} / \mu \mathrm{L}$ ) and incubated at $37^{\circ} \mathrm{C}$ for $2 \mathrm{~h}$. The transcriptions were terminated by addition of an equal volume of TBE-formamide loading buffer (1:9 volume mixture of $1 \mathrm{M}$ Tris- 0.9 M Boric acid$0.01 \mathrm{M}$ EDTA pH 8.4 and formamide), heated $1 \mathrm{~min}$ at $80^{\circ} \mathrm{C}$, chilled on ice, and loaded onto an $18 \%$ denaturing polyacrylamide gel $(39.5 \mathrm{~cm}$ long). The bands were quantitated by storage phosphor technology to determine incorporation ratios, then located by autoradiography, excised from the gel and Cerenkov counted in a Beckman Coulter LS 6500 multi-purpose scintillation counter to determine transcription yields.

Alternatively the transcription reactions were run without addition of $\left[\alpha-{ }^{32} \mathrm{P}\right] \mathrm{CTP}$ and the products were located after gel electrophoresis by UV-shadowing. The bands were excised and the product was extracted from the crushed gel pieces using $0.5 \mathrm{M}$ ammonium acetate (r.t., $15 \mathrm{~h}$ ). The supernatant was filtered and the product recovered by EtOH precipitation. The isolated RNAs were analyzed by MALDI TOF MS:

\begin{tabular}{|c|c|c|}
\hline & Calc $[\mathrm{M}-\mathrm{H}]^{-}$ & Found \\
\hline $\begin{array}{l}\text { RNA = 5'-GG AGC UCA GCC UAC } \\
\text { GAG CCU GAG CC-3' }\end{array}$ & 8247 & 8252 \\
\hline & 8718 & 8722 \\
\hline $\mathrm{O}_{\text {Rnmma }}$ & 8764 & 8764 \\
\hline & 8656 & 8660 \\
\hline $\begin{array}{lll}\text { OII } & 0 \\
\text { a } & \\
\text { RNA }\end{array}$ & 8790 & 8793 \\
\hline
\end{tabular}

\section{References}


(1) Kotch, F. W.; Sidorov, V.; Lam, Y.-F.; Kayser, K. J.; Li, H.; Kaucher, M. S.; Davis, J. T. J. Am. Chem. Soc. 2003, 125, 15140-15150.

(2) Zhu, X.-F.; Williams, H. J.; Scott, A. I. J. Chem. Soc. Perkin Trans. 1 2000, 2305-2306.

(3) Rumney, S. I. V.; Kool, E. T. J. Am. Chem. Soc. 1995, 117, 5635-5646.

(4) Pierce, M. E.; Harris, G. D.; Islam, Q.; Radesca, L. A.; Storace, L.; Waltermire, R. E.; Wat, E.; Jadhav, P. K.; Emmett, G. C. J. Org. Chem. 1996, 61, 444-450. 